\title{
Fairness, self-deception and political obligation
}

\section{Massimo Renzo}

(C) Springer Science+Business Media Dordrecht 2013

\begin{abstract}
I offer a new account of fair-play obligations for non-excludable benefits received from the state. Firstly, I argue that non-acceptance of these benefits frees recipients of fairness obligations only when a counterfactual condition is met; i.e. when non-acceptance would hold up in the closest possible world in which recipients do not hold motivationally-biased beliefs triggered by a desire to free-ride. Secondly, I argue that because of common mechanisms of self-deception there will be recipients who reject these benefits without meeting the counterfactual condition. For this reason, I suggest that those who reject non-excludable benefits provided by the state have a duty to support their rejection with adequate reasons. Failing that, they can be permissibly treated as if they had fair-play obligations (although in fact they might not have them). Thus, I claim that there is a distinction, largely unappreciated, between the question of whether we have a duty of fairness to obey the law and the question of whether we can be permissibly treated as if we had one.
\end{abstract}

Keywords Fair-play · Political obligation · Legitimacy · Presumptive benefits · Non-excludable goods · Self-deception

In the afternoons, Gertrude Stein and I used to go antique hunting in the local shops, and I remember once asking her if she thought I should become a writer. In the typically cryptic way we were all so enchanted with, she said, 'No.' I took that to mean yes and sailed for Italy the next day.

(Woody Allen, “A Twenties Memory”).

The principle of fairness (or fair-play) was first formulated by H.L.A. Hart as follows:

M. Renzo ( $\square)$

Department of Philosophy, University of Warwick, Social Sciences Building,

Coventry CV4 7AL, UK

e-mail:m.renzo@warwick.ac.uk 
[W] hen a number of persons conduct any joint enterprise according to rules and thus restrict their liberty, those who have submitted to these restrictions when required have a right to a similar submission from those who have benefited by their submission (Hart 1955, p. 185).

While Hart's formulation focuses exclusively on the restrictions that membership in a cooperative scheme places upon our liberty, the principle is normally interpreted more expansively, requiring not only that we refrain from certain behaviours, but also that we positively contribute to maintaining the scheme from which we benefit. The more general idea, thus, is that those who benefit from a cooperative scheme incur an obligation to reciprocate by bearing their fair share of the burdens imposed by it.

This is a powerful principle that, for good reasons, has played a major role in the debate on political obligation. Most notably, the principle gives substance to the widespread intuition that our duty to obey the law and maintain the state is ultimately grounded in certain goods that the state provides us with. Of course this intuition is also a tenet of the contractualist view, but while the latter notoriously has the problem of identifying a specific consensual act capable of grounding political obligation, the theory of fair-play does not: it is the very fact that we are part of the cooperative scheme constituted by the state that grounds our duty to do our part in maintaining it, without any need to appeal to an act of consent.

The theory however, has an equally troublesome problem, namely providing an account of the conditions under which fair-play obligations are incurred. Hart claims that merely receiving the benefits provided by the cooperative scheme is sufficient to create such obligations, but this view has been challenged on the grounds that it would allow anyone to place us under an obligation by simply thrusting (more or less desirable) benefits on us (Nozick 1974, pp. 90-95). ${ }^{1}$ For this reason, philosophers such as John Rawls (1964) and John Simmons (2001) have argued that in order to incur a fair-play obligation it is not enough merely to benefit from a cooperative scheme. The benefits must also be accepted, where this means that we either have tried to get (and have succeeded in getting) them or, when this is not possible, we fulfill the psychological condition of taking them 'willingly and knowingly', i.e., that we understand the source and the cost of these benefits, and still want to receive them. Only when one of these conditions is fulfilled do we incur fair-play obligations (Simmons 2001, pp. 18-26). ${ }^{2}$

Simmons' account has been extremely influential, but has also attracted significant criticism, most notably by George Klosko, who argues that the benefits normally provided by the state are 'presumptively beneficial': they are required for a minimally acceptable life and thus we can presume that everyone wants them, regardless of whatever else they want (Klosko 2004, p. 39). Whereas in other

\footnotetext{
1 In this paper I will use the words 'goods' and 'benefits' interchangeably.

2 The focus in the debate is on the second condition. This is because, as it will become clear, we are rarely in a position to try and obtain the benefits produced by the state. Normally these benefits are provided to us without any need on our part to do anything to receive them. For this reason, in the rest of the paper I focus on the second condition and largely ignore the first one.
} 
contexts it is reasonable to require that benefits be accepted in order to ground fairplay obligations, things are different, according to Klosko, in the case of 'presumptive goods'. There is no need to ask whether these have been accepted, because they 'can be presumed to be beneficial without taking the recipients' view into account' (Klosko 2005, p. 51).

My aim in this paper is to offer a new account of the obligations incurred under the principle of fair-play in relation to benefits received from the state, one that strikes a middle path between the 'acceptance-based view' defended by Simmons and the 'receipt-based view' defended by Klosko. ${ }^{3}$ First, I argue that Simmons' account is incomplete, in that there will be cases in which recipients of presumptive goods do not meet his psychological conditions only because they are victims of self-deception. These are recipients who have developed the motivationally-biased mistaken belief that they do not need the benefits provided by the state only because this will enable them to receive those benefits without having to contribute to their production. I contend that this would be unfair and that in this case recipients do have duties of fairness to the state that provides them with those benefits.

I offer a Counterfactual Condition as the criterion to establish who should qualify as a member of a scheme that produces presumptive benefits: what we need to do is consider whether the recipient who declines a certain presumptive benefit would also do so in the closest possible word to the actual one in which she was not affected by self-deceptive beliefs triggered by her desire to free-ride (provided that the two worlds are sufficiently close). Only if she would, can she be said not to be a member of the cooperative scheme and, consequently, not to have fair-play obligations to it.

Second, I draw attention to a distinction, largely unappreciated in the debate, between the question of whether an agent has a duty of fairness and the question of whether she can be permissibly treated as if she had one. I claim that although recipients who meet the Counterfactual Condition cannot be said to have fair-play obligations (in spite of the fact that the goods they receive are presumptively beneficial), it is sometimes permissible to treat them as if they had such obligations. I introduce a second criterion, which I call the Plausible Rejection Condition, to determine when this is the case.

The Plausible Rejection Condition states that in order to be exempted from the obligations normally attached to the receipt of presumptive benefits we must offer plausible reasons in support of our rejection. Only if these reasons adequately support the claim that our rejection is not the product of self-deception, should we be treated as non-members of the scheme.

Discussion is in five sections and a conclusion. In Sect. 1, I criticize the receiptbased view and I raise some initial doubts about the plausibility of the acceptancebased view defended by Simmons. In Sect. 2, I take a closer look at the problems posed by acceptance of non-excludable benefits, focusing in particular on cases where non-acceptance is due to motivationally-biased mistaken beliefs. In Sects. 3 and 4, I introduce and discuss the Counterfactual Condition and the Plausible

\footnotetext{
3 The 'receipt-based view' is also defended in Arneson (1982), Cullity (1995) and Dagger (1997).
} 
Rejection Condition respectively. In Sect. 5, I further elaborate on the second of these conditions.

\section{Receipt-based views vs. acceptance-based views}

The principle of fairness is normally unproblematic in its application to "excludable goods', i.e. goods from whose consumption we can exclude (at low cost) those who have not paid for them. For example, someone who shows up at a potluck without bringing any food is rightfully criticized for taking advantage of other participants' efforts. These cases are easy to deal with because we normally must take steps to receive excludable goods, which are only provided to those who do take such steps. Since the group of those who receive the benefits and the group of those who accept them tend to be extensionally equivalent, the acceptance-based view and the receiptbased view generally converge on how to treat these cases.

Unfortunately, some of the most important goods provided by states, most notably security and the rule of law, are 'non-excludable': they cannot be easily supplied to those who intend to receive them without being supplied at the same time to those who do not. In other words, the group of those who accept the goods is a proper subset of the group of those who receive them, and it is not clear whether fairness obligations are incurred by the latter or only by the former.

Klosko contends that mere receipt of presumptively beneficial non-excludable goods can generate obligations, provided that (a) these goods are worth their costs to their recipients and (b) the costs and the benefits of the cooperative scheme are fairly distributed (Klosko 2005, p. 6). His argument is that since presumptive goods are necessary for any acceptable life, we can presume that everyone would pursue them, if this were necessary to receive them. Given their indispensability it would not be rational not to do so. ${ }^{4}$ And thus, whenever condition (a) and (b) are met, we have a duty of fairness to contribute to the scheme that provides us with such benefits. ${ }^{5}$

This sounds like a version of hypothetical consent, but Klosko explicitly rejects this interpretation of his view, for he claims that the obligation in question does not stem from the fact that we would consent to receive presumptive goods under some idealized conditions (e.g. if we were rational agents) 'but from the fact that [we] receive them' (Klosko 2005, p. 7; Klosko 2004, p. 42). What he means by this is not entirely clear. He writes: 'if we imagine an artificial choice situation analogous to a state of nature, it seems clear that under almost all circumstances ... [we] would choose to receive the benefits at the prescribed cost, if ... [we] had the choice. ... Because of [their] indispensability ... it would not be rational ... [for us] to choose otherwise' (Klosko 2004, pp. 41-42). Doesn't this argument ultimately rely on what we would choose under some idealized conditions, i.e. if we acted rationally? ${ }^{6}$

\footnotetext{
${ }^{4}$ Here I am paraphrasing Klosko (2004, pp. 41-42).

5 In the rest of the paper I will assume that conditions (a) and (b) are always met in the cases I discuss.

6 Notice also that while Klosko presents his view as a receipt-based view, he seems to ultimately appeal to voluntaristic considerations, namely the fact that presumptive good are so important that we can presume that everyone wants them.
} 
But suppose it doesn't, and that there is a way to understand Klosko's last quote so that his argument does not rely on hypothetical consent. Even so, the argument fails. For the fact that a good is necessary for a minimally decent life only shows that anyone acting rationally would want to receive it; not that everyone actually wants to receive it. Since Klosko's view is not supposed to rely on what rational agents would want (idealizing the agents in this way would make his view an instance of hypothetical consent), it is not clear what he expects to derive from his observation that rejecting presumptive benefits would not be rational. Our choices often diverge from what we should rationally choose, and this must be what happens (at least sometimes) with presumptive benefits, given that in fact at least some anarchists typically reject them.

Of course a possible reply here is that whether in fact we want to receive presumptive goods is irrelevant. What matters is that there are good reasons to want them, whether these reasons are recognized or not. I am not sure that Klosko could offer this reply, given how heavily his argument seems to rely on the idea that presumptive goods are such that we can presume everyone to want them, but leaving this worry aside, this reply would be problematic for two reasons. First, it would not be clear, again, in what sense his view is different from hypothetical consent. As many have pointed out, theories of hypothetical consent are not voluntarist theories, for they ultimately ground obligations not in a mysterious act of consent given by individuals placed in certain ideal conditions, but rather in the reasons why consent would be given by these individuals (in the case of political obligation, the fact that states have certain moral qualities and provide important benefits) (Thomson 1990, p. 360). It is hard to see how this position is different from Klosko's, once we understand the latter as the view that presumptive goods ground political obligations in the fact that there are good reasons to want them.

Second, claiming that non-excludable benefits ground obligations for recipients who in fact do not intend to receive them involves an objectionable form of paternalism, since it assumes that we can permissibly limit other people's liberty as a consequence of our imposing on them benefits that they do not want (Wellman 2001 , p. 738). This is at odds with the presumption of liberty typical of liberal theory, i.e., the idea that it should be up to us whether to incur the obligations attached to the enjoyment of certain benefits.

Here it might be replied that freeing from all obligations recipients who do not intend to receive presumptive benefits would be unfair, since it would require a higher contribution from those who do intend to receive them. However, this reply is even more problematic, as it involves a peculiar combination of paternalism and self-interest: on the one hand, it states that we can permissibly limit other people's liberty in order to impose on them benefits they do not want; on the other hand, it justifies the costs that these restrictions inflict on them by appealing to the costs that those who do want to receive the benefits would have to pay otherwise.

For these reasons, I think we should reject the receipt-view. No matter how important certain benefits are, taking individual liberty seriously requires adopting the view that no duty of fair-play can be incurred by those who do not intend to receive them. Acting on the mistaken belief that we can do without these benefits may be imprudent or irrational, but this is not to say that it is also immoral (unless an argument is provided that we have a moral duty to act rationally or to promote our well-being) (Lefkowitz 2006, p. 587). 
But if Klosko's view neglects the importance of individual liberty, Simmons' claim that acceptance of non-excludable goods requires that certain psychological conditions are met (i.e. that the goods are taken 'willingly and knowingly') neglects the importance of the idea that some benefits are presumptively beneficial. Most people will, I think, agree with Klosko that:

(a) certain goods are necessary in order to have a minimally decent life;

(b) being part of some form of cooperative scheme such as the state is the only way to receive these goods; and

(c) states normally provide these goods at a reasonable cost. ${ }^{7}$

Given these assumptions, there is something puzzling in the thought that we should be freed of all obligations simply because we do not have the right psychological conditions toward presumptive goods that we are going to receive anyway. The suspicion is that when these psychological conditions are not met, there might be something wrong with those who do not meet them, rather than with those who expect that they are met. At the very least, more needs to be said about why these conditions are not met.

Interestingly, I think the problem here is that Simmons, like Klosko, does not pay enough attention to recipients who act irrationally, i.e. those who reject presumptive benefits, in spite of the fact that if they acted rationally they would want to receive them. Klosko is too quick in concluding that these recipients have a fairness obligation, even if they do not intend to receive the benefits. In doing so, he does not pay enough attention to the difference between the situation of those who want to receive the benefits and the situation of those who do not. Simmons, on the other hand, is too quick in concluding that those who reject presumptive benefits do not have any obligation, in spite of the fact that rejecting them seems completely irrational. In doing so, he does not pay enough attention to the difference between rejecting presumptive benefits and rejecting other kinds of benefits.

The aim of this paper is to strike a middle way between these two views by advancing an interpretation of the notion of presumptive benefits that is sensitive to the importance of individual preferences in grounding fair-play obligations. I contend that, because of the great value of presumptive benefits, individuals may be presumed to want to receive them. The benefits are only 'presumptively beneficial' because of the possibility that, as things turn out, some recipients may in fact not need them or not view them as actually beneficial. But because of the ordinary conditions of human existence, we may presume that everyone does need them and thus intends to receive them. Consequently, in order for a given individual not to be held to have the obligations that are normally attached to receiving these benefits, she must provide good reasons why she does not need them.

This view acknowledges the importance of Klosko's idea that certain goods are so important that their rejection cannot be taken at face value. At the same time, it

\footnotetext{
7 Of course some will disagree with one or more of these assumptions, but my aim here is not to defend them against the classic objections raised by philosophical anarchists. My aim is to provide the best formulation of the principle of fairness for those who do believe in these assumptions. If these assumptions are not shared, the argument for fair-play does not even begin.
} 
avoids the charge of paternalism, for it acknowledges that no matter how important the goods received, no fairness obligation can be incurred by those who sincerely intend to reject them. Finally, the view does not collapse into a form of hypothetical consent, for it does not idealize recipients by attributing to them desires that they would have if they were perfectly rational. Indeed, the aim of the test I will advance to determine who incurs fair-play obligations is precisely to make these obligations sensitive to the preferences of recipients who hold unusual values and beliefs.

\title{
2 Non-acceptance and self-deception
}

To the view just sketched it might be objected that shifting the burden of proof in the way I suggest is impermissible. The simple fact that someone does not wish to receive a benefit is sufficient to free her from having any obligation of fairness. Consider for example, the following case:

\begin{abstract}
Antidote
A virus spreads in country X. Luckily the government has promptly come up with an antidote: a chemical that needs to be added to the water that goes into everyone's house. Failure to regularly use the water containing the antidote will lead to a premature death. However, producing and distributing the antidote on a regular basis has a significant cost, which all the inhabitants of $\mathrm{X}$ are required to share by paying a special antidote tax. Those who don't pay it will not have the antidote added to their water. ${ }^{8}$ Anna declares that she does not want to receive the antidote.
\end{abstract}

Under such circumstances, Anna does not incur an obligation of fairness, and she does not do so despite the great value of the benefit on offer. Even if we agree that it is irrational for her to refuse the antidote, given that this will lead to a premature death, her refusal clearly prevents her from incurring a fairness obligation to pay for it. If so, should not similar reasoning hold in the case of goods such as national defence or the rule of law? Even if we grant that these goods are presumptively beneficial, should not we conclude that those who do not intend to receive them have no fairness obligations for the same reasons that Anna does not?

Defenders of the receipt-view will reply that the obvious difference here is that while Anna can actually avoid receiving the antidote, goods such as national defence or the rule of law are non-excludable, and so are still received, even when rejected. But consider a second case:

\section{Antidote Received}

This case is similar to Antidote: Anna declines the offer to have the antidote added to her water, despite the fact that she justifiably believes that failing to

\footnotetext{
${ }^{8}$ A few assumptions must be made, for the sake of the argument. These are: (a) that the government can make sure that the water containing the antidote only reaches the houses of those who paid for it; (b) that only one person lives in each house (so that the choice made by those who refuse to pay will not prevent others from receiving the antidote); (c) that the antidote tax is reasonable and that everyone can afford to pay it.
} 
take the antidote will lead to a premature death. However, in this variant of the example, the government has a secret policy of not letting those who don't pay the antidote tax die of a premature death. Thus, all the houses, including Anna's, receive the water with the antidote. This policy is kept secret to encourage everyone to pay the tax.

Whatever else you might think about this case, there is little doubt that Anna still does not incur a fairness obligation. Perhaps you think that secretly providing her with the water containing the antidote is impermissible, as it violates Anna's right to decide for herself whether she should take it or not; perhaps, on the contrary, you think that she has a duty of gratitude grounded in the fact that her life has been saved. I do not intend to consider these questions here. My point is simply that Anna cannot be said to have a duty of fairness despite the fact that (a) the antidote is presumptively beneficial and (b) she cannot avoid receiving it.

In Antidote Received, as in Antidote, it is Anna's choice whether to receive the benefit of the antidote and incur the associated obligations; and her rejection, believing that such rejection will prevent her from receiving the antidote, is clear evidence that she does not want to receive it. Anna's refusal to receive the antidote frees her of any fair-play obligation, despite the fact that she has received an indispensable benefit and that its receipt could not be avoided. But if rejecting excludable goods frees recipients of fairness obligations even when these goods are presumptively beneficial and their receipt cannot be avoided, why should things be different in the case of non-excludable goods provided by the state? Obviously the answer cannot be that the latter are presumptively beneficial and that their receipt cannot be avoided. ${ }^{9}$

This analysis confirms that we should reject Klosko's account. No matter how important certain benefits are, and no matter whether we can avoid receiving them, their mere receipt cannot ground fairness obligation. The conduct ruled out by the principle of fairness consists in taking advantage of the members of a cooperative scheme, i.e. in exploiting the members' sacrifices in order to reap the benefits produced by the scheme without bearing the costs associated with their production. Since in Antidote Received Anna justifiably believes that by rejecting the benefit she will not receive it, it is clear that her rejection is not a way of exploiting the governmental scheme in order to take advantage of those who pay the antidote tax.

On the other hand, things are not as straightforward as presented by Simmons. Consider a third variation on my example:

\section{Insincere Rejection}

The case is similar to Antidote Received, with an important difference: this time Anna does wish to receive the antidote, but she also wishes to avoid paying the antidote tax. Since she has inside information about the secret

\footnotetext{
9 It is important to notice that the benefit received by Anna in Antidote Received meets all the conditions listed by Klosko as sufficient to generate fairness obligations for non-excludable goods (See above, Sect. 1). The antidote is indispensable and it is worth its cost to Anna. We can stipulate that the costs and the benefits of the governmental scheme for the distribution of the antidote are fairly distributed.
} 
governmental policy, she rejects the antidote, knowing that she will receive it nonetheless.

In this case Anna is taking unfair advantage of the governmental scheme, in that she rejects the antidote only because she knows that she will receive it anyway. Under these circumstances, it is clear that she incurs a fair-play obligation, despite her expressed rejection.

Notice that in this case the divergence between expressed and actual preference is possible because of the institutional context, one that in providing benefits to individuals does not discriminate between those who intend to receive them and those who do not. In this context, an agent acting in bad faith can adopt the strategy of rejecting benefits that she is already receiving, or that she knows she is going to receive anyway, because such rejection is enough to free her from obligations that are attached to their acceptance.

Of course this case does not pose a problem for Simmons' view, as in Insincere Rejection Anna does meet the psychological conditions that amount to accepting the benefits. She has a fair-play obligation to pay the antidote tax because she does believe that the antidote is beneficial to her, and she does intend to receive it. She simply lies about what her real beliefs and intentions are in order to game the system. Problems however arise in a case that, although different, shares some important features with Insincere Rejection, i.e. the case of agents who do not lie about their beliefs and intentions, but where the latter are the product of self-deception.

The phenomenon of self-deception is familiar. People sometimes tend to acquire and maintain beliefs that they would like to be true, in spite of the fact that the available evidence, if impartially considered, indicates that they are probably false. In other words, sometimes people trick themselves into believing what they want to be true (Mele 2001; McLaughlin and Rorty 1988). This phenomenon can take different forms. The fact that we desire something to be the case may lead us to:

- not give enough weight to evidence that, absent our desire, we would recognize as important (think of someone who rationalizes the signs available to her that her partner is having an affair);

- read as evidence in support of our desired interpretation, facts that would normally count as evidence against it (this may occur in cases of non-consensual sex in which the wrongdoer believes that by not consenting the victim is only playing a game);

- focus attention on evidence supporting our favored reading of the facts, rather than on evidence against it (think of a job applicant who convinces herself to be the best candidate by concentrating on her strengths, while ignoring both her weaknesses and other candidates' strengths);

- collect hard to find evidence in support of our favored reading of the facts, while overlooking easily accessible evidence against it (think of a mother who closely scrutinizes her son's sources of income, but disregards obvious evidence that he is a drug dealer). ${ }^{10}$

\footnotetext{
${ }^{10}$ Mele labels these mechanisms 'negative misinterpretation', 'positive misinterpretation', 'selective focusing/attending' and 'selective evidence-gathering' (Mele 2001, pp. 26-27).
} 
In all these cases competent epistemic agents (i.e. agents normally capable of collecting and assessing relevant evidence to form justified beliefs) are led by their motivational states to acquire beliefs that they would like to be true in the face of strong evidence to the contrary.

As these examples suggest, psychological mechanisms of this sort are quite common, and can affect human interactions in extremely serious ways. Still they have been neglected so far in the debate on fair-play obligations. This is a mistake, because they raise important issues in regard to the conditions under which such obligations can be incurred. Consider yet another variation of my example:

\section{Self-deception}

This case is identical to Insincere Rejection, with the difference that here Anna is not actively trying to free-ride. She likes to think of herself as a correct person, who would never take advantage of the governmental scheme, but she falls victim to motivationally-biased beliefs such as those described above. Because she does not want to pay the tax, but knows that she will receive the antidote nonetheless, Anna does not accord sufficient weight to the available evidence that she needs the antidote, focusing instead on the signs that mistakenly suggest that she doesn't (say, the fact that she has a particularly strong immune system and she rarely gets sick, or the fact that some people question the real dangerousness of the virus). As a consequence of these processes, she develops the belief that she does not need the antidote and thus forms the intention not to accept it.

Notice that here Anna does acknowledge that she would want to be part of the governmental scheme if she needed the antidote. Her intention not to be part of the scheme is based solely on her motivationally-biased mistaken belief that she does not need it, a belief generated by her desire to receive the antidote without having to contribute to the scheme by paying the antidote tax. Still, as a consequence of holding this motivationally-biased mistaken belief, Anna does not meet Simmons' psychological conditions: she does not take the antidote 'willingly and knowingly'. Should we conclude that she has no obligation of fairness to contribute to the scheme? I think most will agree that this conclusion should be resisted: contra Simmons, if Anna's self-deception is ultimately determined by her desire to freeride, she does have such an obligation despite the fact that she does not meet his psychological conditions.

The qualification that Anna's self-deceptive belief is determined by her desire to free-ride is of course crucial here. For we can think of other kinds of self-deceptive beliefs that might affect Anna's rejection but do not have similar implications. An example would be the case in which Anna's self-deceptive belief was due to the fact that she is so terrorized by the fact that her life is threatened by a virus that she tricks herself into believing that the threat is not real simply because she cannot bring herself to face the situation. In this case Anna could not be said to have any obligation of fairness to the governmental scheme, despite her belief being the product of self-deception, because her rejection of the antidote would be in no way determined by her desire to take advantage of the governmental scheme. It is only when her motivationally-biased belief is grounded in her desire to exploit the 
governmental scheme (as in Self-Deception) that she has can be said to have an obligation of fairness to it. ${ }^{11}$

Since these kinds of psychological processes are quite common, there is reason to believe that they affect at least some of those who reject the benefits provided by the state. Given that these benefits are non-excludable, they are provided to those who intend to receive them as well as to those who do not; but under the acceptance-view, only the former have fairness obligations to contribute to their production. Because of this, agents who wish not to do their part and who are prone to self-deception might develop motivationally-biased beliefs that they do not need the benefits. They might do so by ignoring or downplaying the importance of evidence that, were they not biased, they would recognize as supporting the conclusion that they need them, and focusing instead exclusively on the evidence in favor of the view that they do not. Like Anna in Self-Deception, these individuals acknowledge that they would want to be part of the relevant cooperative scheme, if they needed the benefits. Their intention not to be part of it is based only on the fact that, as a consequence of their desire to free-ride, they have developed the motivationally-biased mistaken belief that they do not need them. An adequate theory of fair-play obligations must account for the fact that these individuals do have such obligations, something that Simmons' view cannot do.

\section{The Counterfactual Condition}

Is there any reason to reject the claim that motivationally-biased mistaken beliefs do not exempt recipients from fair-play obligations (when said beliefs are triggered by a desire to free-ride)? It's hard to see why. The situation of self-deceived recipients is after all not so different from the situation of Anna in Insincere Rejection, the only difference being that the former are not aware of their insincerely rejecting the benefits provided to them, while Anna is.

A plausible way of denying that self-deceived recipients may have fair-play obligations would be to argue that they cannot be said to be morally responsible for their condition, but interestingly very few philosophers take this view. The standard position, shared by intentionalist as well as non-intentionalist accounts of self-deception, is that agents can indeed be held morally responsible for their self-deceptive beliefs. ${ }^{12}$ If so, we should conclude that self-deceived recipients do incur fair-play obligation, and therefore that Simmons' account is at least incomplete. It is not enough to look at whether recipients meet his psychological conditions to establish whether they have an obligation of fairness; for it might well be that someone does not meet these psychological conditions only because she holds motivationally-biased mistaken beliefs, in which case she does have such an obligation.

There is a further question that we need to ask once we know that a certain recipient of non-excludable goods does not meet Simmons' psychological

\footnotetext{
${ }^{11}$ I come back to this point below (Sect. 3). For ease of exposition, in the rest of the paper I will use "self-deception" to mean "self-deception triggered by a desire to free-ride", unless otherwise specified.

12 Prominent examples of non-intentionalist accounts that attribute moral responsibility to self-deceived agents are Barnes (1997) and Mele (2001). For a criticism of the standard view, see Levy (2004).
} 
conditions. We need to ask whether her rejection is genuine or the mere product of self-deception. ${ }^{13}$ More precisely, we need to establish whether the motivationallybiased belief that she doesn't need the benefits is the product of a more or less conscious desire to free-ride. How can we do that? The answer is, I think, this: we take the nearest possible world in which the recipient is not self-deceived because of a desire to free-ride and, assuming that this world is sufficiently close to the actual world (ideally, the two will be identical in all respects except for the fact that the recipient is not self-deceived in the former), we consider whether the recipient would sincerely reject the benefits in this possible world. Only when this Counterfactual Condition is fulfilled, i.e., when the recipient would keep rejecting the benefits in this possible world, may she be said to have genuinely rejected them, and therefore not to have any fair-play obligations. If, by contrast, her rejection of non-excludable goods would not hold up in this possible world, we should conclude that she does have a fair-play obligation to the relevant cooperative scheme. ${ }^{14}$

Imagine, for example, that what motivates Carl's mistaken belief that he does not need national defence is his desire to think that he can provide for his own personal security. In this case the nearest possible world in which Carl is not self-deceived because of a desire to free-ride is the one we live in, and in this world Carl does reject national defence (ex hypothesis). Thus, Carl cannot be said to have an obligation of fairness to contribute to national defence.

Contrast now Carl's case with Philip's. Philip does want to receive national defence, but since he knows that he will receive it anyway, he has developed the motivationally-biased mistaken belief that he does not need it, so that he will not have to contribute to it (in a similar way in which in Self-deception Anna develops the motivationally-biased mistaken belief that she does not need the antidote so that she does not have to pay the antidote tax). Here we need to take the nearest possible world in which Philip does not hold this motivationally-biased mistaken belief - call this world 'world*' —and, assuming that world* is sufficiently similar to our own world, we need to check whether Philip would keep rejecting national defence in world*. If he would, Philip cannot be said to have a fair-play obligation in the actual world; if he wouldn't, he can.

Two points are worth noticing here. First, the clause that world* be sufficiently similar to our own is important. For if world* was too different from our world, it would be harder to derive from the attitudes Philip would hold in world* plausible conclusions about the obligations to be attributed to Philip in the actual world. While generally there is no reason to doubt that the closest possible world in which recipients do not hold motivationally-biased beliefs triggered by a desire to free-ride will be the same in most other respects as the actual world, there might be cases in which they will not. In these cases, according to my view, we cannot attribute any obligation of fairness to recipients who in the actual world decline presumptive benefits out of self-deception.

\footnotetext{
13 Again, this problem does not arise in the cases of excludable goods, whose rejection can be presumed to be genuine, given that it normally precludes their receipt.

14 This argument is modeled on the analysis of truth conditions for counterfactuals pioneered by Lewis (1973). Of course accepting this analysis does not commit one to also accept modal realism.
} 
A particularly interesting case to consider is the following: imagine that in world* Philip would reject national defence, but he would do so because of some reason other than the desire to free ride, reasons that he does not have in the actual world. ${ }^{15} \mathrm{We}$ can imagine, for example, that in world* Philip is a committed pacifist, who thinks that to the extent that national defence requires employing armies, it is morally wrong. This is a reason that, ex hypothesis, Philip does not have in the actual world, since in the actual world Philip does want to receive national defence. He rejects it only as part of an attempt to free ride. I suspect that in this case, world* might not be sufficiently similar to the actual world for us to be able to draw from it any conclusion about the existence of fairness obligation in the actual world. The fact that in world* Philip is not trying to take advantage of the sacrifices made by others, while in the actual world he is, is obviously too significant a difference to be ignored when we are trying to establish which obligations of fairness can be attributed to Philip in the actual world.

Second, remember that here we are interested only in a specific type of selfdeception, i.e., self-deception triggered by a desire to free-ride. ${ }^{16}$ It is important to notice that the counterfactual test is designed precisely to identify this type of selfdeception, which is why Carl passes the test, while Philip doesn't. Both Carl and Philip are self-deceived, but only Philip is self-deceived out of a desire to exploit the cooperative scheme that provides everyone with national defence.

To this it might be objected that this distinction is arbitrary. Why not think that Carl also has a duty of fairness, given that his rejection of national defence is also based on a motivationally-biased mistaken belief (triggered in his case by the desire to think that he can provide for his own personal security)? The answer is that the conduct ruled out by the principle of fairness is that which involves exploiting the sacrifices made by members of a given cooperative scheme in order to take advantage of them by reaping the benefits produced by the scheme without sharing the costs. While Philip is clearly exploiting the scheme that provides him with national defence in this way (despite the fact that he has tricked himself into believing that he is not), Carl is not.

Carl is certainly wrong in believing that he can provide for his own personal security and that he does not need national defence, but to the extent that he hasn't acquired this belief as a way to free-ride on the efforts made by others to contribute to national defence, he cannot be said to be acting unfairly toward them. True, he receives an important benefit for free, while others have to pay for it, but his situation is not different from Anna's in Antidote Received. If we think that Anna does not have a duty of fairness, despite the fact that the antidote she receives is presumptively beneficial and that she cannot avoid receiving it, why think that Carl has a duty of fairness for receiving a good that has the same features $?^{17}$

\footnotetext{
15 Thanks to Christian Barry and Victor Tadros for pressing this point.

16 See above, Sect. 2.

17 For the same reason, obligations of fairness cannot be attributed to those who reject presumptive benefits out of ignorant or misinformed beliefs. There are complexities here that concern how these ignorant beliefs came into existence and whether we can be held at least partially responsible for having them. But, unless they are connected to a desire to exploit the cooperative scheme, they do not trigger a duty of fairness. (Notice that this is in line with our intuitions in Antidote Received. One of the most likely
} 


\section{The Plausible Rejection Condition}

Of course the Counterfactual Condition is not very helpful for practical purposes, since normally there is no way to know whether it is fulfilled. This, however, is no objection to it. Its function after all is to identify the conditions to be met in order to have fair-play obligations for non-excludable goods. That we lack epistemic access as to when these conditions are in fact met is a problem that can in no way affect the correctness of a theory that relies on them. (Compare: the view that good art is that which will stand the test of time cannot by falsified by observing that we generally do not know which art will stand the test of time.)

But even if we are hardly ever in a position to establish whether in fact the Counterfactual Condition is fulfilled, ${ }^{18}$ the view I intend to defend does have important practical implications in relation to the question of which obligations are incurred in the actual world by members of schemes such as the state, as well as the question of what we can legitimately demand of them. The work here is done by the idea that the goods provided by these schemes are presumptively beneficial. These goods are indispensible for minimally decent lives, and thus it is plausible to suppose that everyone wants them, whatever else they want.

As I have argued, the notion of presumptive goods defended by Klosko is flawed because he jumps from the claim that it would not be rational to reject these benefits to the claim that everyone can be said to want them (unless we understand his view as an instance of hypothetical consent). But while this jump is unwarranted, the idea that goods like national defence are such that everyone can be presumed to want them ${ }^{19}$ can play an important role in a theory that grounds political obligation on fairness.

I contend that given that we can justifiably presume that everyone wants to receive these goods, those who intend to reject them must offer plausible reasons in support of their rejection if they want to be exempted from contributing to their production. While normally we cannot permissibly treat someone as a member of a cooperative scheme unless it can be shown that she has accepted the benefits produced by the scheme, this is not true in the case of presumptive benefits. In this case, it is permissible to treat recipients as if they had a fair-play obligation, unless they offer convincing reasons to support the claim that they genuinely reject the benefits.

In other words, the burden of proof, which normally consists in showing that certain benefits have been accepted, is reversed in the case of presumptive nonexcludable goods. It falls on those who claim not to intend to receive the benefits to offer reasons why they do not want to receive them. Since these benefits are

Footnote 17 continued

explanations of the fact that Anna rejects the antidote in that case is that she has a misinformed beliefs about the real dangerousness of the virus.)

18 I say 'hardly ever', because in the same way in which there are cases in which it is clear enough that, say, someone is deceiving herself about her partner's fidelity in order to avoid confronting marital problems, there might be cases in which it is equally clear that someone is deceiving herself about her desiring public goods in order to avoid having to contribute to them. However, I intentionally bracket this consideration here. For the reasons outlined in the previous paragraph, employing the Counterfactual Condition is the right way to assign fair-play obligations for non-excludable goods, even if we could never know when the condition is met.

19 At least when Klosko's two further conditions (above, Sect. 1) are met. 
necessary for minimally decent lives, we have good reasons to presume that everyone wants them, and to suspect that those who claim not to need them (knowing that they will keep receiving them nonetheless) do so as a consequence of motivationally-biased mistaken beliefs.

Notice that this claim is not in conflict with the criterion I have offered in the previous section to determine whether a recipient can be said to have fairness obligation for non-excludable goods. Such a criterion, as we have seen, is whether recipients meet the Counterfactual Condition. This is unaffected by my new claim, for the latter is not that recipients of presumptive benefits have fair-play obligations unless they can offer plausible reasons to support their rejection, but rather that they can be permissibly treated as if they had such obligations unless they do so.

We should distinguish between the question of whether an agent has a duty of fairness and the question of whether she can be permissibly treated as if she had one. The Counterfactual Condition answers the first question (in relation to nonexcludable goods), but not the second. Given that in fact we will hardly ever be in a position to establish whether a given recipient meets the Counterfactual Condition, we need to decide how to deal with her, absent this crucial piece of information. This is where the notion of presumptive benefits kicks in.

Since we can presume that everyone wants these benefits, and they are received whether they are accepted or not, their rejection is likely to be the result of selfdeception (if not of a conscious attempt to free-ride). Because of the advantages of not having to contribute to their production, coupled with the desire not to appear to be a free-rider in our own eyes, we may come to believe that our rejection is sincere, when in fact it is the product of self-deception. The best way to neutralize this mechanism is requiring those who claim not to need the benefits to offer reasons in support of their view (call this the Plausible Rejection Condition). They should explain why they do not want to receive the benefits, while recognizing that nonreceipt would result in their being deprived of goods that are essential in order to lead what is normally considered a minimally acceptable life. Only if recipients can provide plausible reasons of this sort, can they be exempted from contributing to the scheme which provides the benefits. Bare rejection, based on the fact that the psychological conditions spelled out by Simmons are not met, is not enough, because there will be cases in which these psychological conditions are not met as a consequence of self-deception triggered by a desire to free-ride.

In the next section I will expand on what I mean when I say that the reasons offered in support of benefits rejection should be 'plausible', but let me clarify the nature of the Plausible Rejection Condition first. My claim is that what is special about presumptively beneficial goods is not that they ground fair-play obligations irrespectively of their being accepted (as suggested by Klosko), but rather that they ground a duty to provide plausible reasons for their rejection. Rejecting presumptive goods, where this frees recipients from obligations to contribute without precluding at the same time their receipt, is clearly advantageous; and this is likely to work as an incentive to develop the motivationally-biased belief that we do not need the benefits. The point of the Plausible Rejection Condition is to neutralize this process by testing the sincerity of the rejection. 
The simple idea is that when someone rejects presumptively beneficial goods without being able to offer reasons that meet this condition, she is likely to be a victim of self-deception. Of course this conclusion is not certain: we cannot be completely sure that the recipient in question is not being afflicted by other forms of irrationality, ${ }^{20}$ or that she does not have very unusual preferences without being able to articulate a plausible defence for them. Still, I submit that we can be sure enough. Given the crucial importance of presumptive goods and how easily agents develop motivationally-biased beliefs, the most likely explanation in the case of a recipient who does not meet the Plausible Rejection Condition in relation to presumptive goods that she will receive anyway is that she is victim of self-deception; and this is why we can treat her as if she had the relevant obligation.

That there is a slim chance that we will treat someone as if she had an obligation of fairness while in fact she is not the victim of self-deception (of the relevant type) is certainly a moral cost, but one that needs to be paid in order to avoid even higher moral costs. Here I am not thinking so much of the fact that if the group of those afflicted by motivationally-biased beliefs was exempted from contributing to the scheme, the burden that the other members would need to take would be higher. True, since self-deception is quite a common phenomenon, there is reason to believe that the number of those who reject presumptive goods out of self-deception would not be negligible. Still, once redistributed among all other participants, the extraburden imposed on the latter is likely to be only marginally higher. The problem is rather that this extra-burden will then greatly increase for two reasons: first, exempting victims of self-deception from contributing to the scheme would constitute a powerful incentive for others to develop motivationally-biased beliefs. More and more agents would be encouraged to deceive themselves into believing that they do not need those goods they know they are going to receive anyway, but for which they do not have to reciprocate, if they reject them.

Second, such exemption would make the life of intentional free-riders extremely easy, as they would simply need to declare that they do not intend to receive the goods to be let off the hook. This is worrisome not only because conscious freeriders are likely to exploit this mechanism as much as possible, but also because many others will be encouraged to follow their example. Agents who do not care about acting morally will obviously be tempted to become free-riders themselves, given how easy it is to get away with it. But also agents who normally do care about acting morally might be tempted to stop contributing to the scheme whose benefits they accept. They might be tempted to do so for two reasons: some might fear that this would be a waste of their resources, given the suspicion that the number of contributors would be too low to make the scheme beneficial; others will simply refuse to be exploited by contributing to a scheme that counts too many freeriders. ${ }^{21}$ In other words, since the moral reasons we have not to free-ride depend on the fact that we are part of a scheme that fairly distributes burdens and benefits, once

\footnotetext{
20 As we have seen, in cases where self-deception does not ultimately depend on the desire to free-ride, the agent cannot be said to have fair-play obligations.

21 Arneson calls these 'nervous cooperators' and 'reluctant cooperators', respectively (Arneson 1982, pp. 622-623).
} 
it is clear that too many members of the scheme enjoy the benefits without taking on the correlative burdens, many will start thinking that continuing to contribute their part is all but fair.

Although it would be hard to exactly quantify all of this, I think it is reasonable to suggest that once we consider:

- how likely the processes just described are;

- the magnitude of the extra-burden imposed, as a consequence, on law abiding citizens;

and we compare them with:

- how unlikely cases of genuine rejection in which the Plausible Rejection Condition is unmet are;

- the magnitude of the extra-burden imposed on the small number of those who genuinely reject presumptive goods without meeting the Plausible Rejection Condition;

we should conclude that the moral costs identified by the former pair of considerations greatly outweigh the moral costs identified by the latter.

This might sound rather vague, but we often trade off between moral costs precisely in this way. For example, we normally think that it is morally permissible to ask someone who claims to have lost her train ticket to pay again for the fare, in spite of the fact that: (a) we think it is wrong to ask someone to pay twice for the fare, and (b) we know that there will be cases in which the person will have actually bought the ticket and then lost it. Still, allowing anyone who claims to have lost her ticket to travel for free would encourage (literal) free-riders to exploit this policy, and also encourage more people to become free-riders. This is why most companies require that we keep our ticket and make us pay the fare again if we do not. Although this policy certainly has some moral costs (those who lose their ticket have to pay twice), they are less than the moral costs imposed by the policy of allowing anyone who declares to have lost her ticket to travel for free.

Our duty to provide plausible reasons for rejecting presumptively beneficial nonexcludable goods, like our duty to keep our ticket on the train, is justified by the need to provide others with evidence that we are not free-riding, given that exempting us from the relevant moral obligations without requiring us to provide such evidence would have serious moral costs.

\section{Reasons to reject presumptive benefits}

I have argued that the intention not to receive presumptive benefits exempts recipients from fairness obligations only if it is not based on self-deception, and that the only way to show that rejection is not based on self-deception is to support it with plausible reasons. This is why those who intend to reject presumptive benefits have a duty to offer such reasons. If they fail to do so, they can be permissibly treated as if they had fairness obligations, in spite of the fact there is a chance that they do not have them.

Notice that this interpretation of the notion of presumptive benefits does leave room for their rejection. Although we normally expect everyone to want these 
benefits, some may genuinely reject them either because they hold unusual values and prefer enjoying more extensive personal freedom than receiving them, or because they object to the way these benefits are provided. These agents cannot be permissibly treated as if they had fairness obligations, provided that they offer convincing reasons in support of the fact that their rejection is not the product of self-deception. For example, Ben might have strong pacifist religious beliefs and object to security being provided by police and national defence forces. Whether or not this line of argument should be accepted will depend on how convincing Ben's reasons are, but it clearly cannot be ruled out. What matters here is that an argument of this sort is necessary to free him of his obligations. Bare rejection, i.e., the fact that Ben does not meet Simmons' psychological conditions, is not enough.

What does it mean that Ben must provide 'plausible' or 'convincing' reasons? Obviously this cannot mean that these reasons should convince others that he does not need national defence, for this standard could hardly ever be met. Since most people regard national defence as a presumptive benefit, one that everyone needs independently of her specific plan of life, they are unlikely to ever be convinced that Ben does not need it. What matters, however, is that Ben offers adequate reasons in support of the fact that his intention to reject national defence is sincere, rather than the product of selfdeception. He need not convince us that he does not need the benefit. Rather, he must convince us that he is not exploiting our effort to produce this good by maintaining the state. He must convince us that his rejection is not determined by a conscious or unconscious attempt to enjoy national defence without contributing to it.

Of course non-acceptance of presumptive goods may assume different forms. I have argued that if it is supported by plausible reasons, it frees recipients from being treated as if they had fair-play obligations, whereas if it is backed by unconvincing reasons it does not. Between these poles are more difficult cases in which the intention to reject benefits is defended by reasons that have different degrees of (im)plausibility. While it is obviously not enough for Ben to say that he does not need the British military establishment because he holds a black belt in karate, how should we treat him if he appeals to the fact that he is a member of a mutual protective association of the type discussed by Nozick (1974, pp. 54-56)?

Distinguishing between plausible and implausible reasons can be extremely difficult, and this paper is not the occasion for detailed assessment of particular claims concerning whether or not given goods are needed, or to establish precise criteria for such cases. No doubt, some cases will be controversial. Still, many will not: there are reasons that can be confidently classified as plausible or implausible. To be acceptable, reasons offered in support of rejection of presumptive goods must be of the first kind. When they are implausible, we are likely to be dealing either with a conscious attempt to free-ride or with a case of self-deception, which is why recipients can be permissibly treated as if they had fairness obligations. Once again, this is not because recipients' intention to reject the benefits is not important, but rather because the reasons they offer are not strong enough to overcome the presumption that their rejection is based on self-deception (if not on a conscious attempt to free-ride).

As a rule, the strength of the presumption that everyone wants a certain benefit is directly proportional to the importance of the benefit and inversely proportional to 
the likelihood that it could be secured without the state. And the stronger the presumption that everyone wants the benefit, the stricter the standard of adequacy that must be met in order not to incur a fairness obligation. Thus, while a relatively easy case could be made, for example, to support rejection of state protection from natural calamities (wealthy citizens would only need to show that they are privately equipped to deal with most of these calamities), the standard for what counts as a credible evidence of the fact that we do not need benefits such as the rule of law or national defence is much harder to meet.

In a recent paper Klosko has addressed some of the worries I raise here (Klosko 2014). Like me, Klosko believes that motivationally-biased beliefs cannot exempt beneficiaries of non-excludable goods from fairness obligations. Moreover, like me, he believes that recipients of presumptive benefits who intend to reject such benefits ought to make a convincing case for the claim that they don't need the benefits, if they are to be exempted from contributing to their production. Thus, at first sight our positions might seem quite close. It is important to notice that they are not.

Whereas Klosko claims that those who cannot provide convincing reasons in support of their rejection of presumptive benefits do have fair-play obligations, I only claim that they can be treated as if they had them. Whether in fact they have the obligation only depends on whether they meet the Counterfactual Condition, and has nothing to do with their ability to provide adequate reasons for their rejection.

Klosko does not include anything like the Counterfactual Condition in his view and mistakenly uses what I call the Plausible Rejection Condition as a the criterion to decide who has fair-play obligations. This is because he conflates the question of when we can permissibly treat people as if they had fairness obligation with the question of when they can be said to have such obligations.

Nor should my view be assimilated to a variant of hypothetical consent, for the reason why recipients who do not meet the Counterfactual Condition incur fair-play obligations is not that they would want to receive the benefits if they were perfectly rational. My view is sensitive to "the eccentricities of individual uptake" (Simmons 2001, p. 148) because it does not idealize agents by attributing to them preferences or desires that they should have or that they would have if they were perfectly rational. Rather, recipients' preferences and desires are taken for what they are, namely the product of imperfect agents. Indeed, the role of the Counterfactual Condition is precisely to help us correctly identify these preferences and desires by neutralizing mistaken beliefs that are manufactured (more or less consciously) in order to mask them.

This is why my view can account for the fact that recipients who, like Ben, hold unusual values or have unusual preferences do not incur fairness obligations for presumptive benefits. This also explains why my view is not subject to the charge of paternalism. As long as someone's rejection of presumptive benefits is sincere, she does not incur obligations of fairness, even if it would be good for her to accept those benefits.

\section{Conclusion}

I have argued that although non-acceptance of excludable goods frees one of fairness obligations she would otherwise have, non-acceptance of presumptively 
beneficial non-excludable goods does so only if the recipient is not a victim of selfdeception (triggered by a desire to free-ride). The criterion to determine whether this is the case is the Counterfactual Condition: only recipients who would keep rejecting the benefits in the closest possible world in which they do not hold motivationally-biased beliefs triggered by a desire to free-ride, can be said not to have a fairness obligation (assuming that this possible world is sufficiently close to the actual world).

Unfortunately, however, we normally have no epistemic access to this information. For this reason we need a second criterion that works as a proxy, i.e. a test that tells us whether a given agent is likely to be sincere in her rejection. This is the role of the Plausible Rejection Condition: recipients who intend to reject presumptive goods must support their rejection by reasons that satisfy a standard of adequacy. Most likely, victims of self-deception will not be able to offer reasons that meet this standard, and so may be treated as if they had the relevant obligations.

I have granted that there might be cases of recipients who genuinely intend to reject certain presumptive goods, but are unable to provide convincing reasons to support the sincerity of their rejection. I acknowledge that requiring these recipients to contribute to the production of the goods in question, despite the fact that they do not have an obligation of fairness to do so (insofar as they do not meet the Counterfactual Condition) is a significant moral cost. However, I have argued that this moral cost is outweighed by the higher moral costs that would derive from allowing recipients to avoid the obligations normally attached to receiving presumptive benefits without having to meet the Plausible Rejection Condition. ${ }^{22}$

This view is faithful to the spirit of the voluntarist reading of the principle of fairplay offered by Simmons, for it acknowledges that, no matter how important the goods received, no fairness obligation can be incurred by those who sincerely intend to reject them. At the same time, the view acknowledges the importance of Klosko's idea that certain goods are so fundamental that we should be skeptical of those who reject these goods too lightly, knowing that they will receive them anyway. Given the nature of presumptive goods, we can justifiably presume that everyone wants to receive them, and thus treat recipients as if they had the relevant obligations, unless they offer plausible reasons in support of their rejection.

In conclusion, I want to stress an important consequence of this view for the question of how we should understand political authority. Political authority is normally conceived as involving the right to impose and enforce binding duties on those who are subject to it (Simmons 2001, p. 130). According to this traditional conception, having political authority is having a claim-right, which correlates to the citizens' duty to obey the law, i.e., political obligation. However, this view is sometimes criticized as too demanding. Political authority, according to some, should be understood instead as a liberty-right, i.e., as a right to issue commands and

\footnotetext{
22 Notice that the reverse case, although unlikely, is also possible. It might be that someone who does not meet the Counterfactual Condition deceives herself to the point that she can indeed offer reasons that would pass the Plausible Rejection Condition. This person does have a fair-play obligation, but since we do not have access to this information, we cannot know that it would be permissible for us to treat her accordingly.
} 
enforce them, where this does not entail that subjects have a duty to obey (Ladenson 1980). Indeed, some go as far as to say that those subject to this kind of political authority may justifiably attempt to escape state coercion (Christiano 2008).

Which of these understandings is more plausible is a debated question (Knowles 2010, pp. 24-28), but there is no reason to exclude that they could be both valid. Indeed, this is what would follow from adopting the conception of fair-play I develop in this paper. If this conception is correct, we should conclude that the state has a claim-right to rule over those who accept its benefits (by meeting Simmons's psychological conditions), as well as over those who reject them but fail to meet the Counterfactual Condition. The latter have a duty of fairness to maintain the state no less than the former, since their rejection is the product of self-deception.

Moreover, the state has a liberty-right to enforce its laws over those who meet the Counterfactual Condition, but fail to meet the Plausible Rejection Condition. Although in fact they do not have a fair-play obligation to obey the law and maintain the state, these individuals can be justifiably treated as if they had such obligation because they could not provide convincing reasons to rebut the presumption that they want to receive the goods provided by it.

Finally, the state has no authority over those who meet both the Counterfactual Condition and the Plausible Rejection Condition. These are the only individuals who are not subject to the authority of the state in virtue of the presumption that they need the benefits provided by it. Of course this is not to say that they cannot be subject to the authority of the state on different grounds. As I argue elsewhere (Renzo 2011, 2012), we should be pluralist about legitimacy and political obligation: different, sometimes overlapping, principles justify political authority over different individuals. The aim of this paper was to show that the principle of fair-play is one of these principles.

Acknowledgments Earlier versions of this paper were presented at the University of Warwick, at the Australian National University, at an IVR Special Workshop on Political Obligation in Frankfurt and at the 2012 MANCEPT workshops. I am grateful to participants at these events for stimulating discussions. I am especially grateful to Christian Barry, Peter Chau, Matthew Clayton, Richard Dagger, Antony Duff, John Horton, Matthew Kramer, Conor McHugh, Fabienne Peter, Victor Tadors, Bas Van Der Vossen and an anonymous reviewer for very helpful written comments. Finally, I would like to thank George Klosko, who co-authored a number of early versions of this paper, before we realized that our positions could not be reconciled.

\section{References}

Arneson, R. (1982). The principle of fairness and free-rider problems. Ethics, 92, 616-633.

Barnes, A. (1997). Seeing through self-deception. New York: Cambridge University Press.

Christiano, T. (2008). Authority. In E. N. Zalta (Ed.), The Stanford encyclopedia of philosophy. http:// plato.stanford.edu/archives/fall2008/entries/authority/.

Cullity, G. (1995). Moral free riding. Philosophy \& Public Affairs, 24, 3-34.

Dagger, R. (1997). Civic virtues: Rights, citizenship and republican liberalism. Oxford: Oxford University Press.

Hart, H. L. A. (1955). Are there any natural rights? Philosophical Review, 64, 175-191.

Klosko, G. (2004). The principle of fairness and political obligation (2nd ed.). Savage, MD: Rowman and Littlefield.

Klosko, G. (2005). Political obligations. Oxford: Oxford University Press. 
Klosko, G. (2014). Fairness obligations and non-acceptance of benefits. Political Studies (forthcoming). Knowles, D. (2010). Political obligation. London: Routledge.

Ladenson, R. (1980). In defence of a Hobbesian conception of law. Philosophy \& Public Affairs, 9, $134-159$.

Lefkowitz, D. (2006). The duty to obey the law. Philosophy Compass, 1, 571-598.

Levy, N. (2004). Self-deception and moral permissibility. Ratio, 17, 294-311.

Lewis, D. K. (1973). Counterfactuals. Oxford: Blackwell.

McLaughlin, B. P., \& Rorty, A. O. (Eds.). (1988). Perspectives on self-deception. Berkeley, CA: University of California Press.

Mele, A. (2001). Self-deception unmasked. Princeton, NJ: Princeton University Press.

Nozick, R. (1974). Anarchy, state, and utopia. New York: Basic Books.

Rawls, J. (1964). Legal obligation and the duty of fair play. In S. Hook (Ed.), Law and philosophy (pp. 3-18). New York: New York University Press.

Renzo, M. (2011). State legitimacy and self-defence. Law and Philosophy, 30, 575-601.

Renzo, M. (2012). Associative responsibilities and political obligation. Philosophical Quarterly, 62, $106-127$.

Simmons, A. J. (2001). Justification and legitimacy: Essays on rights and obligations. Cambridge: Cambridge University Press.

Thomson, J. J. (1990). The realm of rights. Cambridge, MA: Harvard University Press.

Wellman, C. H. (2001). Toward a liberal theory of political obligation. Ethics, 111, 735-759. 